\title{
Reprocessing semicritical items: Current issues and new technologies
}

\author{
William A. Rutala PhD, MPH, CIC a,b,*, David J. Weber MD, MPH a,b \\ a Hospital Epidemiology, University of North Carolina Health Care, Chapel Hill, NC \\ b Division of Infectious Diseases, University of North Carolina School of Medicine, Chapel Hill, NC
}

Key Words:

Endoscopes

disinfection

sterilization

cystoscopes

semicritical

\begin{abstract}
Semicritical medical devices are defined as items that come into contact with mucous membranes or nonintact skin (eg, gastrointestinal endoscopes, endocavitary probes). Such medical devices minimally require high-level disinfection. Because many of these items are temperature sensitive, low-temperature chemical methods are usually used rather than steam sterilization. Strict adherence to current guidelines is required because more outbreaks have been linked to inadequately cleaned or disinfected endoscopes and other semicritical items undergoing high-level disinfection than any other reusable medical device.
\end{abstract}

In the United States in 2010, there were approximately 51.4 million inpatient surgical procedures and an even larger number of invasive medical procedures. ${ }^{1}$ For example, there were $>6.9$ million upper gastrointestinal (GI), 11.5 million lower GI, and 228,000 biliary endoscopies performed in $2009 .{ }^{2}$ Each of these procedures involves contact by a medical device or surgical instrument with a patient's sterile tissue or mucous membranes. A major risk of all such procedures is the introduction of pathogenic microbes, which can lead to infection. Failure to properly disinfect or sterilize equipment may lead to transmission via contaminated medical and surgical devices (eg, carbapenemresistant Enterobacteriaceae [CRE]).,

Multiple studies in many countries have documented the lack of compliance with established guidelines for disinfection and sterilization. ${ }^{5}$ Failure to comply with scientifically based guidelines has led to numerous outbreaks and patient exposures. In fact, nearly all infections and patient exposures associated with reprocessing medical or surgical instruments involve high-level disinfection (HLD) of reusable semicritical items ${ }^{6-8}$ Because of noncompliance with recommended reprocessing procedures, the Centers for Disease Control and Prevention (CDC) and the Food and Drug Administration (FDA) issued a health advisory alerting health care providers and facilities about the public health need to properly maintain, clean, disinfect, and sterilize reusable medical devices in September $2015 .{ }^{9}$ In this

\footnotetext{
* Address correspondence to William A. Rutala, PhD, MPH, CIC, Hospital Epidemiology, Occupational Health, and Safety Program, UNC Health Care, Room 1001 West Wing, Chapel Hill, NC 27514.

E-mail address: brutala@unch.unc.edu (W.A. Rutala).

Publication of this article was supported by an educational grant from Clorox Healthcare, Sealed Air, and Tru-D. Content of this article was initiated and written by the authors with no input or financial support to the authors from Clorox Healthcare, Sealed Air, or Tru-D.

Conflicts of Interest: Dr Rutala is a consultant for Clorox and has received honoraria from 3M. Dr Weber is a consultant for Clorox and Germitec.
}

expanded and updated version of a previous article on this subject, ${ }^{10}$ we will examine new technologies and issues for HLD of semicritical items. Because semicritical items carry the greatest risk of infection we also will discuss reprocessing semicritical items, such as endoscopes (and automated endoscope reprocessors [AERs]), nasopharyngoscopes, endocavitary probes, prostate biopsy probes, tonometers, laryngoscopes, transesophageal echocardiogram probes, infrared coagulation devices, and urologic instruments.

\section{A RATIONAL APPROACH TO DISINFECTION AND STERILIZATION}

Almost 50 years ago, Spaulding ${ }^{11}$ devised a rational approach to disinfection and sterilization of patient care items or equipment. This classification scheme is so clear and logical that it has been retained, refined, and successfully used by infection control professionals and others when planning methods for disinfection or sterilization. ${ }^{12-15}$ Spaulding believed that the nature of disinfection could be understood more readily if instruments and items for patient care were divided into 3 categories based on the degree of risk of infection involved in the use of the items. The 3 categories he described were critical (enters sterile tissue and must be sterile), semicritical (contact with mucous membranes and requires HLD), and noncritical (comes in contact with intact skin and requires lowlevel disinfection). Although the scheme remains valid, there are some examples of disinfection studies with viruses, mycobacteria, and protozoa that challenge the current definitions and expectations of high- and low-level disinfection. ${ }^{16}$

\section{Semicritical items}

Semicritical items are those that come in contact with mucous membranes or nonintact skin. Respiratory therapy and anesthesia 
equipment, GI endoscopes, bronchoscopes, laryngoscopes, transesophageal echocardiogram (TEE) probes, tonometers, endocavitary probes, prostate biopsy probes, ${ }^{17}$ cystoscopes, hysteroscopes, infrared coagulation devices, and diaphragm fitting rings are included in this category. These medical devices should be free of all microorganisms (ie, mycobacteria, fungi, viruses, bacteria); however, small numbers of bacterial spores may be present. Intact mucous membranes, such as those of the lungs or the GI tract, generally are resistant to infection by common bacterial spores but susceptible to other organisms, such as bacteria, mycobacteria, and viruses. Semicritical items minimally require HLD using chemical disinfectants. Glutaraldehyde, hydrogen peroxide, orthophthalaldehyde, peracetic acid, and peracetic acid with hydrogen peroxide, and a chlorine-based system are cleared by the FDA ${ }^{18}$ and are dependable high-level disinfectants provided the factors influencing germicidal procedures are met. The exposure time for most high-level disinfectants varies from $8-45$ minutes at $20^{\circ} \mathrm{C}-25^{\circ} \mathrm{C} .{ }^{18}$ When a disinfectant is selected for use with certain patient care items, the chemical compatibility after extended use with the items to be disinfected also must be considered.

Because semicritical equipment has been associated with reprocessing errors that result in patient lookback and patient notifications, it is essential that control measures be instituted to prevent patient exposure. ${ }^{7}$ Before new equipment (especially semicritical equipment as the margin of safety is less than that for sterilization $)^{19}$ is used for patient care on $>1$ patient, reprocessing procedures for that equipment should be developed. Staff should receive training on the safe use and reprocessing of the equipment and be competency tested. At the University of North Carolina Hospitals, to ensure patient-safe instruments, all staff that reprocess semicritical instruments (eg, instruments which contact a mucous membrane, such as vaginal probes, endoscopes, and prostate probes) are required to attend a 3-hour class on HLD of semicritical instruments. The class includes the rationale for and importance of HLD, discussion of HLD and exposure times, reprocessing steps, monitoring minimum effective concentration, personal protective equipment, and reprocessing environment (establish dirtyto-clean flow). Infection control rounds or audits should be conducted annually in all clinical areas that reprocess critical and semicritical devices to ensure adherence to the reprocessing guidelines, manufacturers' instructions for use, and institutional policies. This includes reprocessing critical and semicritical medical and surgical instruments in outpatient care facilities because many patient exposures and infections have occurred in this setting. ${ }^{20,21}$ Results of infection control rounds should be provided to the unit managers, and deficiencies in reprocessing should be corrected and the corrective measures documented to infection control within 30 days. However, patient safety issues (such as wrong contact time, temperature, or concentration of high-level disinfectant) require immediate correction.

Semicritical items that will have contact with mucous membranes should be rinsed with sterile water or filtered water or tap water followed by an alcohol rinse. ${ }^{15,22}$ An alcohol rinse and forced air drying markedly reduces the likelihood of contamination of the instrument (eg, endoscope), most likely by removing the wet environment favorable for bacterial growth. ${ }^{23}$ After rinsing, items should be dried and stored in a manner that protects them from damage or contamination. Drying also retards biofilm formation. ${ }^{24}$

Semicritical items represent the greatest risk of disease transmission because far more health care-associated infections have been caused by reusable semicritical items than critical or noncritical items. ${ }^{25}$ There is virtually no documented risk of transmitting infectious agents to patients via noncritical items ${ }^{26}$ when they are used as noncritical items and do not contact nonintact skin or mucous membranes. Similarly, critical items are rarely, ${ }^{27}$ if ever, associated with disease transmission. In contrast, semicritical items (eg, GI endoscopes), by virtue of the body cavities they enter, may contain $10^{7-10}$ (7-10 $\log _{10}$ ) enteric microorganisms. ${ }^{28,29}$ Therefore, any deviation from proper reprocessing (eg, crevices associated with the elevator channel of a duodenoscope) could lead to failure to eliminate contamination with a possibility of subsequent patientto-patient transmission. This low (or nonexistent) margin of safety associated with endoscope reprocessing compares with the $17 \log _{10}$ margin of safety associated with cleaning and sterilization of surgical instruments. ${ }^{19,25}$ This is the reason that semicritical items represent the greatest risk of disease transmission via a reusable medical or surgical instrument and critical items are rarely, ${ }^{27}$ if ever, associated with infection.

\section{REPROCESSING SEMICRITICAL ITEMS}

\section{Reprocessing of endoscopes}

Physicians use endoscopes to diagnose and treat numerous medical disorders. Although endoscopes represent a valuable diagnostic and therapeutic tool in modern medicine, more health careassociated outbreaks and patient exposures have been linked to contaminated endoscopes than to any other reusable medical device. ${ }^{6,8}$ Additionally, endemic transmission of infections associated with GI endoscopes may go unrecognized for several reasons, including inadequate surveillance of outpatient procedures, long lag time between colonization and infection, low frequency of infection, and the pathogens transferred by the endoscope are the usual enteric flora. In addition, the infection risk of some procedures might be lower than others (eg, colonoscopy vs endoscopic retrograde cholangiopancreatography [ERCP]) where normally sterile areas are contaminated in the latter. To prevent the spread of health carassociated infections, all heat-sensitive endoscopes (eg, GI endoscopes, bronchoscopes, nasopharyngoscopes) must be properly cleaned and, at a minimum, subjected to HLD after each use. HLD can be expected to destroy all microorganisms; however, when high numbers of bacterial spores are present, a few spores may survive.

Recommendations for the cleaning and disinfection of endoscopic equipment have been published and should be strictly followed. ${ }^{15,22,30}$ Unfortunately, largely because of instrument complexity, audits have shown that personnel do not adhere to guidelines on reprocessing ${ }^{5}$ and outbreaks of infection continue to occur. ${ }^{3,4,6,8,31}$ Additionally, recent studies have suggested that current reprocessing guidelines are not sufficient to ensure successful decontamination, ${ }^{32}$ and some AERs have been recalled because of violations that include the inability of the unit to validate that the AER can adequately wash and disinfect endoscopes to mitigate the risk of patient infection. ${ }^{33}$ To minimize patient risks and ensure that reprocessing personnel are properly trained, there should be initial and annual competency testing for each individual who is involved in reprocessing endoscopic instruments. ${ }^{15,22,30}$

In general, HLD of an endoscope involves the following 5 steps after leak testing: (1) clean-mechanically clean internal and external surfaces, including brushing internal channels and flushing each internal channel with water and an enzymatic cleaner or detergent; (2) disinfect-immerse endoscope in a high-level disinfectant (or chemical sterilant) and perfuse (eliminates air pockets and ensures contact of the germicide with the internal channels) disinfectant into all accessible channels, such as the suction or biopsy channel and air or water channel and expose for a time recommended for the specific products; (3) rinse-rinse the endoscope and all channels with sterile water, filtered water (commonly used with AERs), or tap water; (4) dry-rinse the insertion tube and inner 
channels with alcohol and dry with forced air after disinfection and before storage; and (5) store-store the endoscope in a way that prevents recontamination and promotes drying (eg, hung vertically). ${ }^{15,22}$

Outbreaks of CRE infection associated with duodenoscopes: What can we do to prevent infections?

In the last 3 years, multiple reports of outbreaks have led the FDA, CDC, and national news to raise awareness among the public and health care professionals that the complex design of duodenoscopes (used primarily for ERCP) may impede effective reprocessing. Several recent publications have associated multidrugresistant bacterial infections, especially CRE in patients who have undergone ERCP, with reprocessed duodenoscopes. ${ }^{3,4,19,31,34,35}$ Unlike other endoscope outbreaks, ${ }^{6}$ these recent outbreaks occurred even when the manufacturer's instructions and professional guidelines were followed correctly.,4

The key concern raised by these outbreaks is that current reprocessing guidelines are not adequate to ensure a patient-safe GI endoscope (one devoid of potential pathogens) because the margin of safety associated with reprocessing endoscopes is minimal or nonexistent. There are at least 2 (and maybe 3 ) reasons for this reprocessing failure and why outbreaks continue to occur. ${ }^{19}$ First, studies have shown that the internal channel of GI endoscopes, including duodenoscopes, may contain $10^{7-10}$ (7-10 $\log _{10}$ ) enteric microorganisms. ${ }^{28,29}$ Investigations have demonstrated that the cleaning step in endoscope reprocessing results in a $2-6 \log _{10}$ reduction of microbes and the HLD step results in another 4-6 $\log _{10}$ reduction of mycobacteria for a total $6-12 \log _{10}$ reduction of microbes. ${ }^{28,29,36}$ Therefore, the margin of safety associated with cleaning and HLD of GI endoscopes is minimal or nonexistent (level of contamination: $4 \log _{10}$ [maximum contamination, minimal cleaning/HLD] to $-5 \log _{10}$ [minimum contamination, maximum cleaning/HLD]). Therefore, any deviation from proper reprocessing (eg, crevices associated with the elevator channel) could lead to failure to eliminate contamination with a possibility of subsequent patient-to-patient transmission. This low (or nonexistent) margin of safety associated with endoscope reprocessing compares with the $17 \log _{10}$ margin of safety associated with cleaning and sterilization of surgical instruments. ${ }^{19}$

Second, GI endoscopes not only have heavy microbial contamination $\left(10^{7}-10^{10}\right.$ bacteria) but they are complex, with long, narrow channels; right angle turns; and difficult to clean and disinfect components (eg, elevator channel). The elevator channel in duodenoscopes is unique to side-viewing endoscopes. It has a separate channel and provides orientation of catheters, guide wires, and accessories into the endoscopic visual field. ${ }^{19}$ This channel is complex in design and has crevices that are difficult to access with a cleaning brush and may impede effective reprocessing. ${ }^{37}$ Based on this and other recent studies, it is likely that multidrug-resistant pathogens are acting as a marker or indicator organism for ineffective reprocessing of the complex design of duodenoscopes, which is an infectious risk to patients.

Third, biofilms could impact endoscope reprocessing failure and continued endoscope-related outbreaks. ${ }^{38}$ Biofilms are multilayered bacteria plus exopolysaccharides that cement cells to surfaces. They develop in a wet environment. If reprocessing is performed promptly after use and the endoscope is dry, the opportunity for biofilm formation is minimal. ${ }^{39,40}$ However, the formation of endoscopic biofilm during clinical practice may be related to reuse of reprocessing methods, such as reuse of detergent, manual cleaning, and incomplete drying. ${ }^{41}$ Ideally, reprocessing should be initiated with an hour of use; however, there are no evidence-based guidelines on delayed endoscope reprocessing. ${ }^{42}$ It is unclear if biofilms contribute to failure of endoscope reprocessing.
What should we do now? Unfortunately, there is currently no single, simple, and proven technology or prevention strategy that hospitals can use to guarantee patient safety. Of course, we must continue to emphasize the enforcement of evidence-based practices, including equipment maintenance and routine audits in areas that reprocess semicritical items (eg, GI, urology), with at least yearly competency testing of reprocessing staff. ${ }^{15,22,30}$ All reprocessing personnel must be knowledgeable and thoroughly trained on the reprocessing instructions for duodenoscopes. This includes the new recommendations to use a small bristle cleaning brush and for additional flushing and cleaning steps of the elevator channel. ${ }^{43}$ Although these steps were described as validated, no public data are available on the ability of these new cleaning recommendations to yield an ERCP scope devoid of bacteria. However, we must do more or additional outbreaks will likely continue. For example, all hospitals that reprocess duodenoscopes should select one of the enhanced methods for reprocessing duodenoscopes. These enhanced methods have been priority ranked with the first providing the greatest margin of safety. ${ }^{19}$ They include the following: (1) ethylene oxide sterilization after HLD with periodic microbiologic surveillance; (2) double HLD with periodic microbiologic surveillance; (3) HLD with scope quarantine until negative culture results are returned; (4) liquid chemical sterilant processing system using peracetic acid (rinsed with extensively treated potable water) with periodic microbiologic surveillance; (5) other FDA-cleared low-temperature sterilization technology (provided material compatibility and sterilization validation testing performed using the sterilizer and endoscope) after HLD, with periodic microbiologic surveillance; and (6) HLD with periodic microbiologic surveillance. These supplemental measures to enhance duodenoscope reprocessing made in May-June $2015^{19}$ were reinforced by the FDA in August 2015. ${ }^{37}$ University of North Carolina Hospitals have chosen ethylene oxide sterilization after HLD with periodic microbiologic surveillance as its primary reprocessing method for duodenoscopes, and if the ethylene oxide sterilizer is not available, then double HLD with periodic microbiologic surveillance is performed. ${ }^{44}$

Infection preventionists should ensure that institutional policies are consistent with national guidelines and manufacturers' instructions for use and conduct infection control rounds periodically (eg, at least annually) in areas where endoscopes and other semicritical items are reprocessed to make certain there is compliance with policy. Breaches in policy should be documented and corrective action instituted. In incidents in which endoscopes and other semicritical items were not exposed to a HLD process, patients were assessed for possible acquisition of HIV, hepatitis B virus, and hepatitis $C$ virus. A 14-step method for managing a failure incident associated with HLD or sterilization has been described. ${ }^{7}$ The possible transmission of bloodborne pathogens and other infectious agents highlights the importance of rigorous infection control. ${ }^{21,45,46}$

\section{Nasopharyngoscopes}

Flexible nasopharyngoscopes are a valuable tool enabling easy visualization of the upper aerodigestive tract. The following 3 techniques are available to reprocess nasopharyngoscopes: manual HLD, use of an AER, and use of a disposable sheath. ${ }^{15,47,48}$ However, because sheaths, condoms, or covers may have tears or breaks that compromise their integrity, there was hesitation to allow the use of a sheath to alter the recommendation of HLD. Now, there are 2 peerreviewed publications that validate the integrity of the sheath with nasopharyngoscopes.

One study showed that the use of a high-quality, snugly fitting, sterile, disposable polyurethane sheath on nasopharyngoscopes 
during a clinical examination, combined with enzymatic detergent cleaning and disinfection with $70 \%$ ethanol, provided a reliably decontaminated, patient-ready instrument which eliminated the need for HLD of nasopharyngoscopes. ${ }^{49}$ Another study found that the contamination rate on nasopharygolaryngoscopes (FNPLs) with the sheath alone was similar to the contamination rate with the highlevel disinfected scope. The authors concluded that using the individually packaged disposable sterile sheath of a FNPL prevented microbes from adhering to the shaft of the scope, therefore providing a safe method of avoiding the transmission of infection from one patient to the next patient when using a FNPL successively in multiple patients in an otolaryngology clinic. ${ }^{50}$ Because we now have 2 studies that corroborate the integrity of the sterile polyurethane sheaths used with nasopharyngoscopes, this practice (use of a high-quality, snugly fitting, sterile, disposable sheath on a nasopharyngoscope during a clinical examination, combined with enzymatic detergent cleaning and disinfection with 70\% ethanol) can provide a reliably decontaminated, patient-ready instrument and may be an option for HLD. Therefore, we believe that with this specific sheath and this device (ie, nasopharyngoscope), this practice of using this sheath plus cleaning plus alcohol may be an option for HLD.

\section{Tonometers}

Disinfection strategies for other semicritical items (eg, applanation tonometers, rectal or vaginal probes) are highly variable. Currently, the FDA requests that the device manufacturer include at least 1 validated cleaning and disinfection-sterilization protocol in the labeling for their device. As with all medications and devices, users should be familiar with the label instructions. In view of the potential for transmission of viruses (eg, herpes simplex virus, adenovirus type $8, \mathrm{HIV})^{51}$ by tonometer tips, the $\mathrm{CDC}$ recommended ${ }^{52}$ that the tonometer tips be wiped clean and disinfected for 5-10 minutes with either 3\% hydrogen peroxide, 5,000 ppm chlorine, 70\% ethyl alcohol, or 70\% isopropyl alcohol. However, data demonstrate that 3\% hydrogen peroxide and 70\% isopropyl alcohol are not effective against adenovirus capable of causing epidemic keratoconjunctivitis and similar viruses and should not be used for disinfecting applanation tonometers. ${ }^{53-55}$ For this reason, the CDC guideline now recommends to wipe clean tonometer tips and then disinfect them by immersing for 5-10 minutes in either 5,000 ppm chlorine or $70 \%$ ethyl alcohol. ${ }^{15,52-55}$ Structural damage to Schiotz tonometers has been observed with a 1:10 sodium hypochlorite (5,000 ppm chlorine) and 3\% hydrogen peroxide. ${ }^{56}$ After disinfection, the tonometer should be thoroughly rinsed in tap water and air dried before use. We believe that wiping the tonometer tips with only a 70\% isopropyl alcohol wipe is insufficient because 2 reports have found that disinfection of pneumotonometer tips between uses with a 70\% isopropyl alcohol wipe contributed to outbreaks of epidemic keratoconjunctivitis caused by adenovirus type $8 .^{57,58}$

\section{Endocavitary probes}

Vaginal probes are used in sonographic scanning. A vaginal probe and all endocavitary probes without a probe cover are semicritical devices because they have direct contact with mucous membranes (eg, vagina, rectum, pharynx). Although one could argue that the use of the probe cover changes the category, the CDC guideline for disinfection and sterilization proposes that a new condom or probe cover should be used to cover the probe for each patient, and because condoms and probe covers may fail, ${ }^{59-63}$ HLD of the probe also should be performed. ${ }^{15}$ The relevance of this recommendation is reinforced with the findings that sterile transvaginal ultrasound probe covers have a very high rate of perforations even before use $\left(0 \%, 25 \%\right.$, and $65 \%$ perforations from 3 suppliers). ${ }^{62}$ After oocyte retrieval use, Hignett and Claman found a very high rate of perforations in used endovaginal probe covers from 2 suppliers (75\% and $81 \%),{ }^{62}$ whereas Amis et $\mathrm{al}^{64}$ and Milki and Fisch ${ }^{59}$ demonstrated a lower rate of perforations after use of condoms $(0.9 \%$ and $2.0 \%$, respectively). Rooks et al found that condoms were superior to commercially available probe covers for covering the ultrasound probe (1.7\% leakage for condoms vs $8.3 \%$ leakage for probe covers). ${ }^{65}$ These studies underscore the need for HLD of endocavitary probes between examinations. Although most ultrasound manufacturers recommend the use of $2 \%$ glutaraldehyde for HLD of contaminated transvaginal transducers, the use of this agent has been questioned ${ }^{66}$ because it may shorten the life of the transducer and may have toxic effects on the gametes and embryos. ${ }^{67}$ An alternative procedure for disinfecting the vaginal transducer has been offered by Garland and de Crespigny. ${ }^{68}$ It involves the mechanical removal of the gel from the transducer, cleaning the transducer in soap and water, wiping the transducer with $70 \%$ alcohol or soaking it for 2 minutes in $500 \mathrm{ppm}$ chlorine, and rinsing with tap water and air drying. The effectiveness of this method has not been validated in rigorous laboratory experiments. Another probe disinfection method that uses a ultraviolet $C$ chamber has been evaluated and is used in Europe, but it is not yet FDA-cleared for use in the United States. 63,69

HLD with a FDA-cleared high-level disinfectant (eg, accelerated hydrogen peroxide) that is not toxic to staff, patients, probes, and retrieved cells should be used until such time as the effectiveness of alternative procedures against microbes of importance at the cavitary site is demonstrated by well-designed experimental scientific studies. Other probes such as rectal, cryosurgical, and transesophageal probes and devices should also be subjected to HLD between patients.

Ultrasound probes may also be used during surgical procedures and have contact with sterile body sites. These probes may be covered with a sterile sheath to reduce the level of contamination on the probe and reduce the risk of infection. However, because the sheath does not provide complete protection of the probe, the probes should be sterilized between each patient use as with other critical items. If this is not possible, minimally high-level disinfect the probe and cover it with a sterile probe cover.

Some cryosurgical probes (eg, used in prostate cancer) are not fully immersible. When reprocessing these probes, the tip of the probe should be immersed in a high-level disinfectant for the appropriate time (eg, 20 minutes of exposure with $2 \%$ glutaraldehyde), and any other portion of the probe that could have mucous membrane contact should be disinfected by immersion or wrapping with a cloth soaked in a high-level disinfectant to allow for the recommended contact time. After disinfection, the probe should be rinsed with tap water and dried before use. Health care facilities that use nonimmersible probes should replace them as soon as possible with fully immersible probes.

As with other HLD procedures, proper cleaning of probes is necessary to ensure the success of the subsequent disinfection. ${ }^{70}$ Muradali et al demonstrated a reduction of vegetative bacteria inoculated on vaginal ultrasound probes when the probes were cleaned with a towel. ${ }^{71}$ No information is available on either the level of contamination of such probes by potential viral pathogens, such as hepatitis B virus and human papilloma virus, ${ }^{72}$ or their removal by cleaning (eg, with a towel). Because these pathogens may be present in vaginal and rectal secretions and contaminate probes during use, HLD of the probes after such use is recommended.

The CDC guideline for disinfection and sterilization states that even if probe covers have been used, clean and high-level disinfect the semicritical devices, such as rectal probes, vaginal probes, and cryosurgical probes, with a product that is not toxic to staff, 
patients, probes, and retrieved germ cells (if applicable). Use a highlevel disinfectant at the FDA-cleared exposure time unless scientific studies and guidelines recommend an alternative time and temperature (eg, glutaraldehyde at 20 minutes, $\left.20^{\circ} \mathrm{C}\right) .{ }^{15,22}$ When probe covers are available, use a probe cover or condom to reduce the level of microbial contamination. Do not use a lower category of disinfection or cease to follow the appropriate disinfectant recommendations when using probe covers because these sheaths and condoms may fail (see the exception for nasopharyngoscopes and 1 tested sheath previously mentioned). After HLD, rinse all items. Use sterile water, filtered water, or tap water followed by an alcohol rinse for semicritical equipment that will have contact with the mucous membranes of the upper respiratory tract (eg, nose, pharynx, esophagus). ${ }^{15}$

\section{Hydrogen peroxide mist system for probes}

An alternative procedure for disinfecting the endocavitary and surface probes is a hydrogen peroxide mist system, which uses 35\% hydrogen peroxide at $56^{\circ} \mathrm{C}$ with the probe reaching no more than $40^{\circ} \mathrm{C}$ (ie, Trophon EPR; Nanosonics, Fishers, Fall Creek, IN). In one study, the results demonstrated complete inactivation $\left(>6 \log _{10}\right.$ reduction) of vancomycin-resistant Enterococcus and a CRE-Klebsiella pneumoniae strain both in the presence and absence of $5 \%$ fetal calf serum (FCS). The Trophon EPR system showed good, but not complete, inactivation of Mycobacterium terrae (5.2 $\log _{10}$ reduction for $M$ terrae with FCS and $4.6 \log _{10}$ reduction for $M$ terrae without FCS) and Clostridium difficile spores (5.1 $\log _{10}$ reduction for $C$ difficile spores with FCS and $6.2 \log _{10}$ reduction for $C$ difficile spores without FCS). ${ }^{73}$ To simulate a worst-case condition, cleaning was not done prior to disinfection in these experiments, but proper cleaning of probes is necessary to ensure the success of HLD. Other data have demonstrated the activity of the Trophon system to inactivate human papilloma virus ${ }^{74}$ and other pathogens (eg, bacteria, mycobacteria, viruses), including a $>6 \log _{10}$ reduction of $M$ terrae and $C$ difficile spores in carrier tests and $\mathrm{a}>6 \log _{10}$ reduction in $M$ terrae on inoculated ultrasound probes. ${ }^{75}$ These results differ slightly from those previously mentioned, presumably because of the differences in testing methodology. In our study only the probe devices were inoculated (carriers of different materials were not tested), and for recovery of bacteria on the probe, the probes were immersed in media (not swabbed, which would likely result in lower recovery). ${ }^{73}$ The Trophon system processes the portion of the probe that has mucous membrane contact but also the handle of the endocavitary probe, which may be contaminated, and it is an alternative to highlevel chemical disinfection for ultrasound probes.

\section{Prostate biopsy probes}

Transrectal ultrasound-guided prostate biopsies are among the most common outpatient diagnostic procedures performed in urology practice to evaluate patients for prostate cancer after an elevated prostate-specific antigen level or abnormal digital rectal examination findings. ${ }^{76}$ It involves obtaining multiple prostate tissue cores by passing a disposable biopsy needle through a needle guide under ultrasound guidance. All prostatic biopsy procedures result in contamination of the probe with blood or feces. During this procedure, the transducer assembly is generally covered with a barrier sheath. ${ }^{77}$ Breaches in the reprocessing of prostate biopsy probes can pose a risk of disease transmission. ${ }^{76,78}$

Disinfection or sterilization of ultrasound transducer components is based on the function or use of each component. Because the biopsy needle penetrates sterile tissue for biopsy, it should be sterile. Ideally, the needle guide should be sterilized between patient use. However, if this is not possible (ie, clinic does not have a sterilizer because biopsy needles are likely purchased as single-use sterile devices), then HLD after disassembly and cleaning is acceptable because it has contact with mucous membranes but not sterile tissue. The FDA alert ${ }^{77}$ and a CDC article ${ }^{76}$ recommend that the needle guide be sterilized because the biopsy needle contacts the needle guide before it penetrates sterile tissue. This recommendation is inconsistent with current recommendation for the disinfection of GI endoscopes. It is currently recommended that GI endoscopes be highlevel disinfected minimally but that medical devices that pass through the endoscope and enter sterile tissue (eg, biopsy forceps) be sterilized. ${ }^{15,22}$ There is no recommendation that the lumen or channel through which they pass should also be sterilized. One possible explanation for the inconsistency in this FDA recommendation is that the GI endoscopes can only be high-level disinfected because there is no practical way to sterilize them, whereas the reusable needle guide for prostate probes can be sterilized (M.J. Arduino, August 2006, written communication). Although a barrier sheath is used on the transducer assembly during the biopsy procedure, the sheath is compromised by the penetration of the needle. ${ }^{77} \mathrm{Al}$ though prostate probes and other endocavitary probes are often covered with a disposable sheath or condom, ${ }^{77}$ such covers do not adequately protect the probe from microbial contamination caused by leakage $(9 \%)^{79}$; therefore, the use of a cover does not alter the requirement for minimal HLD. ${ }^{15}$ The FDA specifies the use of a sterile barrier sheath in their recommendation for reprocessing reusable ultrasound transducer assemblies. ${ }^{77}$ It is appropriate to use a sterile barrier sheath when an ultrasound probe is entering a sterile body cavity, but when the probe is entering the rectum, the need for a sterile barrier sheath is unclear.

All semicritical and critical medical devices must be thoroughly cleaned with enzymatic or nonenzymatic detergents before they are subjected to a HLD or sterilization process, respectively. Brushes should be used, when possible, to effectively clean the transducer assemblies, especially the lumens. Our investigation shows that the needle guide and prostate probe can be effectively disinfected with glutaraldehyde, but the needle guide must be disassembled from the transducer assembly before HLD. ${ }^{17}$

The FDA issued a Public Health Notification in June 2006 as a result of follow-up to the Department of Veterans Affairs, Veterans Health Administration Patient Safety Alert related to a particular company's ultrasound transducer assemblies. During patient safety rounds, the lumen of a needle guide of an ultrasound transducer assembly was found to be soiled. The FDA guidance consisted of several steps ${ }^{80}$ for the complete method recommend by the FDA). We have evaluated the FDA steps and suggest some modifications (Table 1). Do not reuse items labeled for single use (eg, single-use biopsy needles, needle guides). Additional recommendations may be available in the operator's manuals or user guides. It is important that these recommendations be consistent with disinfection and sterilization guidelines and principles or that these recommendations have been validated by appropriate scientific studies. Do not use any disinfectant that can cause irreparable damage to the materials used to construct the probe. For example, if an alcohol rinse is not compatible with the probe, rinse with sterile water (not filtered water or tap water) and do not rinse with alcohol. These recommendations could be adapted to all ultrasonic prostate probes to include those with an external needle guide attachment.

\section{Transesophageal echocardiogram probes (TEE)}

The TEE probe is another semicritical device that has a potential for infection between sequential patients. Two bacterial outbreaks (Escherichia coli and Pseudomonas aeruginosa) have been associated with damaged TEE probes used in cardiovascular surgical operations. ${ }^{81,82}$ Once the damaged TEE probes were removed from use, no additional cases were identified in the cardiac surgery pa- 
Table 1

Recommendation for reprocessing the transrectal ultrasound prostate biopsy probes*

Cleaning
- Clean immediately after use
- Disassemble the transducer (remove needle guide from the probe)
Brush clean (if possible) or flush each lumen and thoroughly clean all
detergent
- Rinse with tap water
- Dry with disposable cloth or towel or air dry
- Visibly inspect the entire device to ensure it is clean
High-level disinfection or sterilization
- Steam sterilize all heat-stable reusable components
- Alternatively, high-level disinfect the probe and needle guide separately
after disassembly
- High-level disinfect all heat-sensitive components (ensure disinfectants
reach all areas inside the lumens, and the minimum effective
concentration of the high-level disinfectant is monitored)
- Rinse with sterile water, filtered water, or tap water (FDA specifies sterile
- water for rinsing)
immersion of the probe in alcohol) to enhance drying (and no residual
- water is left for microbial growth)
- Appropriately store the device to ensure the device is not recontaminated
- Aprenter

FDA, Food and Drug Administration.

*Users should be familiar with the manufacturer's recommendations for use and disinfection of the specific device used by the facility.

Adapted with permission from Cambridge University Press. ${ }^{17}$

tients. The defect presumably prevented exposure of the bacteria to the high-level disinfectant. To ensure proper HLD, health care facilities should ensure the probe is not damaged and comply with recommendations from professional organizations and the manufacturer. The basic principles for successful reprocessing of the probe involve the following: clean the probe shaft and probe tip (via immersion or wiped with a wipe moistened with detergent or enzymatic cleaner) to remove gross contamination (a second wipe is used to wipe nonimmersible parts higher up, including the handle); inspected to ensure no structural damage; disinfect with a high-level disinfectant (distal tip and flexible shaft are immersed in the high-level disinfectant; wipe the higher portions with a compatible disinfectant); thoroughly rinse; and dry before storage. ${ }^{83}$ Protective sheaths are an additional physical barrier to infection and probe damage; however, they do not remove the possibility of infection because sheaths do not cover all of the TTE probes and the sheaths are subject to perforations. ${ }^{84}$ Strict adherence to manufacturers' instructions when using chemical disinfectants such as orthophthalaldehyde for TEE probe reprocessing is required to avoid aerodigestive tract chemical injury. ${ }^{85}$ TEE probes require HLD regardless of whether a sheath is used. Many hospitals use a vapor control system that reduces exposure of staff to toxic vapors and damage to the instrument (eg, wall rack holder such as a glutaraldehyde user station). Follow the manufacturer's instructions or professional organizational guidelines for soak times, cleaners, and so forth.

\section{Infrared coagulation}

Infrared coagulation is a widely used method for treating hemorrhoids. The procedure involves applying infrared light to compress and seal hemorrhoid veins. The manufacturer of the device sells a sterile disposable sheath and states removing and soaking light guides between procedures is no longer required. The manufacturer also states that the light guide is damaged by immersion in a disinfectant because the light guide is not sealed at the end and the disinfectant gets between the quartz glass and the covering.
As mentioned, the CDC guideline recommends immersion for reprocessing endocavitary probes with covers because integrity of the cover is compromised. Because the light guide cannot be immersed, we investigated an alternative procedure. This procedure involved wiping the probe for 2 minutes with a 1:10 bleach (5,000 ppm), and after that is completed, the probe is wiped with sterile water and air dried. This procedure has been found effective in eliminating approximately $7 \log _{10}$ reduction $\left(7.8 \times 10^{6}\right)$ of $M$ terrae and is used at our hospital for decontamination of the sheathed device after use. ${ }^{86}$

\section{Laryngoscopes}

Laryngoscopes are routinely used to view the vocal cords and larynx and facilitate airway management. It typically consists of a blade that connects to a handle which usually contains 2 batteries that power the light source. Limited guidelines are available for reprocessing laryngoscope blades and handles, and hospital practices vary. ${ }^{87-89}$ For example, some guidelines recommend and hospitals use low-level disinfection of the handle because it does not have direct contact with a mucous membrane, whereas others recommend the handle be high-level disinfected to prevent disease transmission. Although blades have been linked to health careassociated infections, handles have not been directly linked to health care-associated infections. However, reports of contamination with blood (40\% of the handles were positive for occult blood) and potentially pathogenic microorganisms ( $86 \%$ of the handles deemed "ready for patient use" were positive for Staphylococcus aureus, Acinetobacter spp, etc) suggest the handles infection risk, ${ }^{89-92}$ and the blade and handle function together. For this reason, it is ideal that the blades and handles be high-level disinfected or sterilized even if a protective barrier or sheath is used during the procedure. In 2007, the State of California required that both blades and handles be HLD or sterilized. UNC Hospitals are sterilizing the blades and handles (ie, blades sterilized via hydrogen peroxide gas plasma, handle [without batteries] sterilized by steam). Other methods for HLD or sterilization are acceptable, but ensure the blade and handle are compatible with the HLD or sterilization process chosen. After sterilization, the blades and handles are checked for function prior to packaging and then packaged in a sealed plastic bag. Per The Joint Commission, the laryngoscope blade and handle must be packaged in a way that prevents recontamination after processing (Frequently Asked Questions from The Joint Commission October 24, 2011). Examples of compliant storage include, but are not limited to, a peel pack poststerilization (long-term storage) or wrapping in a sterile towel (short-term storage).

Recent advances in video technology have led to the development of video laryngoscopes, such as the GlideScope (Verathon, Seattle, WA) and McGRATH MAC (Covidien; Medtronic, Minneapolis, MN) video laryngoscopes. These new intubation devices assist in difficult airway management. For the McGRATH MAC, an image is displayed on a liquid-crystal display screen that is contained within a monitor mounted to the handle of the device. A sterile, singleuse disposable laryngoscope blade covers the camera and lightemitting diode assembly to prevent direct patient contact. Even though a cover is used, HLD or sterilization via ethylene oxide or hydrogen peroxide gas plasma (battery removed) is recommended for the McGRATH MAC video laryngoscope. ${ }^{93}$ The manufacturer states, whenever practical, HLD or sterilization is preferred to a wipebased process.

The portable GlideScope video laryngoscope system is available in a single-use and a reusable configuration. It should be cleaned and disinfected per the manufacturer's recommendations. The singleuse system features a reusable video baton and sterile Stats that must be disposed of immediately after use. Low-level disinfection 
is recommended for the video baton after each use using an Environmental Protection Agency-registered disinfectant (eg, antimicrobial disposable wipe per the manufacturer's instructions). HLD is recommended by the manufacturer for the video baton when it is visibly soiled.

The manufacturer recommends that the advanced video laryngoscope reusable blade be high-level disinfected and the GlideRite rigid stylets be sterilized. ${ }^{94}$

\section{Other channeled endoscopes (cystoscopes, ureteroscopes, and hysteroscopes)}

In the United States, it is estimated that $>4$ million cystoscopies are performed each year. Cystoscopy is a diagnostic procedure that uses an endoscope especially designed to examine the bladder, lower urinary tract, and prostate gland or is used to collect urine samples, perform biopsies, and remove small stones. A flexible or rigid scope can be used to carry out the procedure. Because the procedure involves a medical device in contact with the patient's mucous membranes, it is considered a semicritical device that must minimally be high-level disinfected. Failure to properly high-level disinfect or sterilize equipment can lead to transmission of infection..$^{95,96}$

A recent study demonstrated how important it is to perfuse the high-level disinfectant into the channel of cystoscopes and other channeled scopes (eg, hysteroscopes, ureteroscopes). This study demonstrated that disinfection (ie, a reduction in bacterial load of $>7$ $\log _{10}$ colony forming units) did not occur unless the channel was actively perfused with glutaraldehyde. In fact, failure to perfuse the channel led to only minimal, if any, reduction in bacterial contamination. However, complete inactivation of $10^{8}$ colony forming units of both vancomycin-resistant Enterococcus and CRE was achieved when the channel was actively perfused. It appears that no highlevel disinfectant entered the channel unless it was actively perfused because the level of microbial contamination was not reduced by immersion. This occurs because the air pressure in the channel is stronger than the fluid pressure at the fluid-air interface. Recommendations are provided for cystoscope HLD and include actively perfusing the device while immersed in the high-level disinfectant. ${ }^{96}$

Cystoscopes have also been implicated as the source of infection in multiple patients when incorrect disinfection methods were identified. ${ }^{95}$ This may, in part, be related to the lack of awareness of recommendations specifically for disinfecting cystoscopes ${ }^{97}$ or failing to follow the manufacturer's instructions, which specify perfusing the lumen using a high-level disinfectant. Unfortunately, some cystoscope reprocessing recommendations published in the literature are incorrect. For example, authors have recommended complete immersion of the cystoscope into the high-level disinfectant, but they did not mention perfusion of the high-level disinfectant into the channel. ${ }^{95}$ We suggest following our recommendations (Table 2) and those of the American Urological Association ${ }^{97}$ until evidence-based guidelines have been published. Anaphylactic reactions have been reported in patients with bladder cancer who underwent repeated cystoscopy using scopes that were HLD with ortho-phthalaldehyde; therefore, orthophthalaldehyde is contraindicated in patients with a history of bladder cancer. ${ }^{97}$

\section{Other issues affecting semicritical items}

\section{Storage of semicritical items}

In 2011, The Joint Commission recommended that laryngoscope blades be packaged in a way that prevents recontamination. Examples of compliant storage include, but not limited to, a peel

Table 2

Recommendations for reprocessing a flexible cystoscope*

- Preclean: immediately (within $1 \mathrm{~h}$ ) after use to reduce microbes and organic matter. Gross debris should be wiped off the outside of the scope using a soft, disposable cloth or sponge and water with an enzymatic or nonenzymatic detergent. Channels should be flushed with the same solution.

- Pressure/leak testing: should be performed to ensure that the flexible covering and the channels are intact. It should be done after each use and before reprocessing, according to manufacturer's guidelines.

- Clean: carefully clean channels with suitable cleaning brushes (see manufacturer's recommendations) and flush or rinse to remove any loosened organic matter; thoroughly clean all external surfaces using a soft, disposable cloth or brush with enzymatic or nonenzymatic detergent. Again, water with an enzymatic or nonenzymatic detergent should be used for cleaning and flushing the channels. Detachable parts of the cystoscope, such as valves, adapters, and caps, should be removed according to the manufacturer's recommendations prior to cleaning and high-level disinfection.

- Rinse with tap water

- Dry with soft, lint-free cloth or towel (preferably disposable) or air dry

- Visibly inspect the entire device to ensure it is clean

- Reusable brushes should be high-level disinfected after each use

- Because enzymatic and nonenzymatic detergents are not microbicidal, they should be discarded after each use

- High-level disinfection

- High-level disinfect the cystoscope by completely immersing in the high-level disinfectant and perfusing the high-level disinfectant through the channel using a syringe that luer-locks onto the scope port. Actively fill the channel and syringe multiple times with the high-level disinfectant until no air bubbles exist in the scope or the syringe. The scope should remain submerged.

- The exposure time and temperature for disinfecting patient care equipment varies among the FDA-cleared high-level disinfectants. Follow the FDA-cleared label claim for high-level disinfection unless several well-designed experimental scientific studies, endorsed by professional societies, demonstrate an alternative exposure is effective for disinfecting semicritical items. Multiple scientific studies and professional organizations support the efficacy of $>2 \%$ glutaraldehyde for 20 minutes at $20^{\circ} \mathrm{C} .{ }^{22,25}$ Perform routine testing (eg, before each use, daily, per manufacturer's recommendations) of the liquid high-level disinfectant to ensure at least the minimum effective concentration of the active ingredient.

- Rinse with sterile water: if filtered water or tap water is used, follow with an alcohol rinse (not immersion of the cystoscope in alcohol) to enhance drying (and no residual water is left for microbial growth)

- Dry the device: dry all channels with medical grade forced air until the air is dry; dry the outside with a lint-free disposable cloth

- Storage: appropriately store the device to ensure the device is not recontaminated

- When using high-level disinfectants, personal protective equipment should be worn as recommended (eg, gloves, gown, faceshield)

- If an AER is used, ensure that the manufacturer's recommended channel connectors are properly used

Sterilization

- Alternatively, low-temperature sterilization technology (eg, ethylene oxide, hydrogen peroxide plasma) may be an option for heat-sensitive equipment, such as cystoscopes, but the user must comply with the cystoscope and sterilizer manufacturer's recommendations

$A E R$, automated endoscope reprocessor; FDA, Food and Drug Administration.

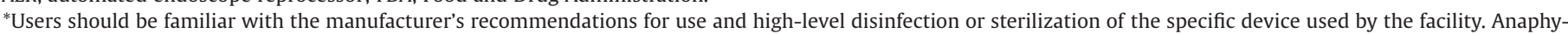

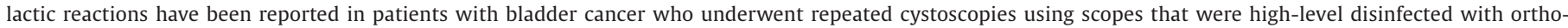
phthalaldehyde; consequently, ortho-phthalaldehyde is contraindicated in patients with a history of bladder cancer.Adapted from Cambridge University Press. ${ }^{96}$ 
pouch or a closed plastic bag. Examples of noncompliant storage would include unwrapped blades in an anesthesia drawer and an unwrapped blade on top of or within a code cart. The packaging not only prevents recontamination but also distinguishes a processed from a nonprocessed semicritical item, such as a specula, laryngoscope blade, or endoscope. The use of a tagging system that separates processed from nonprocessed items minimizes the use of semicritical items that have not been reprocessed and prevents patient exposure to a nonreprocessed semicritical item. ${ }^{7}$ This could involve a tag (eg, green tag: patient ready, red tag: requires reprocessing) for GI endoscopes or a plastic sheath or plastic-paper peel pouch (eg, endocavitary probes). Ideally, hospitals and ambulatory care facilities (as appropriate) ${ }^{20}$ should develop a strategy (eg, tagging, storage covers for patient-ready devices) that prevents patient exposure to contaminated devices.

\section{Human papilloma virus}

Human papilloma virus is an extremely common sexually acquired infection and is the most important cause of cervical cancer. A recent article demonstrated that the FDA-cleared high-level disinfectants (ie, glutaraldehyde, ortho-phthalaldehyde) tested did not inactivate the human papilloma virus, a nonenveloped virus. ${ }^{98}$ These findings are inconsistent with many articles in the peer-reviewed literature, which demonstrate that HLD, such as by OPA and glutaraldehyde, inactivates nonenveloped viruses, such as human papilloma virus, polio, adenovirus, norovirus, and so forth. ${ }^{15}$ Because HLDs are commonly used to disinfect endocavitary probes (eg, vaginal probes, rectal probes), there is an urgency to corroborating these data. In a conversation with CDC staff regarding this issue, it was determined hospitals should continue to use the FDAcleared high-level disinfectants consistent with the manufacturers' instructions until the data can be corroborated. Data have demonstrated the activity of a hydrogen peroxide mist device to inactivate the human papilloma virus. ${ }^{74}$

\section{Do not reuse single-use devices}

The Department of Justice and the FDA have joined forces in prosecuting health care providers that reuse single-use devices. For example, a physician was criminally prosecuted for reusing needle guides meant for single use during prostate procedures. These prosecutions are based on conspiracy to commit adulteration and Medicare fraud. Third-party reprocessing is allowed by the FDA when the reprocessor is considered the device manufacturer, as defined under 21 CFR Part 820.

\section{CONCLUSIONS}

Strict adherence to current guidelines is required for semicritical items because more outbreaks have been linked to inadequately cleaned or disinfected semicritical items, such as endoscopes, undergoing HLD than any other reusable medical device.

\section{References}

1. Centers for Disease Control and Prevention. National hospital discharge survey: 2010 table, Procedures by selected patient characteristics-number by procedure category and age. Atlanta, GA: Centers for Disease Control and Prevention; 2010.

2. Peery AF, Dellon ES, Lund J, Crockett SD, McGowan CE, Bulsiewicz WJ, et al. Burden of gastrointestinal disease in the United States: 2012 update. Gastroenterology 2012;143:1179-87.

3. Epstein L, Hunter JC, Arwady MA, Tsai V, Stein L, Gribogiannis M, et al. New Delhi metallo-beta-lactamase-producing carbapenem-resistant Escherichia coli associated with exposure to duodenoscopes. JAMA 2014;312:144755 .

4. Wendorf KA, Kay M, Baliga C, Weissman SJ, Gluck M, Verma P, et al. Endoscopic retrograde cholangiopancreatography-associated AmpC Escherichia coli outbreak. Infect Control Hosp Epidemiol 2015;36:634-42.
5. Ofstead CL, Wetzler HP, Snyder AK, Horton RA. Endoscope reprocessing methods: a prospective study on the impact of human factors and automation. Gastroenterol Nurs 2010;33:304-11.

6. Kovaleva J, Peters FT, van der Mei HC, Degener JE. Transmission of infection by flexible gastrointestinal endoscopy and bronchoscopy. Clin Microbiol Rev 2013;26:231-54.

7. Rutala WA, Weber DJ. How to assess risk of disease transmission to patients when there is a failure to follow recommended disinfection and sterilization guidelines. Infect Control Hosp Epidemiol 2007;28:146-55.

8. Weber DJ, Rutala WA. Lessons learned from outbreaks and pseudo-outbreaks associated with bronchoscopy. Infect Control Hosp Epidemiol 2012;33: 230-4.

9. Centers for Disease Control and Prevention. Immediate need for healthcare facilities to review procedures for cleaning, disinfecting, and sterilizing reusable medical devices. 2015. Available from: http://emergency.cdc.gov/han/ han00382.asp. Accessed October 16, 2015.

10. Rutala WA, Weber DJ. New developments in reprocessing semicritical items. Am J Infect Control 2013;41(Suppl):S60-6.

11. Spaulding EH. Chemical disinfection of medical and surgical materials. In: Lawrence C, Block SS, editors. Disinfection, sterilization, and preservation. Philadelphia (PA): Lea \& Febiger; 1968:517-31.

12. Rutala WA, Weber DJ. Disinfection, sterilization and control of hospital waste. In: Bennett JE, Dolan R, Blaser MJ, editors. Principles and practice of infectious diseases. Philadelphia (PA): Elsevier Saunders; 2015:3294-309.

13. Rutala WA, Weber DJ. Disinfection and sterilization: an overview. Am J Infect Control 2013;41(Suppl):S2-5.

14. Rutala WA, Weber DJ. Cleaning, disinfection and sterilization. In: Grota P, editor. APIC text of infection control and epidemiology. 4th ed. Washington, DC: Association for Professionals in Infection Control and Epidemiology, Inc; 2014:31.1-15.

15. Rutala WA, Weber DJ, HICPAC. Guideline for disinfection and sterilization in healthcare facilities, 2008. Centers for Disease Control and Prevention; 2008 Available from: http://www.cdc.gov/hicpac/pdf/guidelines/Disinfection_Nov 2008.pdf. Accessed October 15, 2015.

16. McDonnell G, Burke P. Disinfection: is it time to reconsider Spaulding? J Hosp Infect 2011;78:163-70.

17. Rutala WA, Gergen MF, Weber DJ. Disinfection of a probe used in ultrasoundguided prostate biopsy. Infect Control Hosp Epidemiol 2007;28:916-9.

18. Food and Drug Administration. FDA-cleared sterilants and high level disinfectants with general claims for processing reusable medical and dental devices, March 2015. 2015. Available from: http://www.fda.gov/MedicalDevices/ DeviceRegulationandGuidance/ReprocessingofReusableMedicalDevices/ ucm437347.htm. Accessed October 15, 2015.

19. Rutala WA, Weber DJ. ERCP scopes: what can we do to prevent infections? Infect Control Hosp Epidemiol 2015;36:643-8.

20. Bringhurst J. Disinfection and sterilization in physician practices and specialty clinics. Am J Infect Control 2016; In press.

21. Centers for Disease Control and Prevention. Healthcare-associated hepatitis B and hepatitis C outbreaks reported to the Centers for Diseases Control and Prevention (CDC) 2008-2014. 2015. Available from: http://www.cdc.gov/hepatitis/ outbreaks/healthcarehepoutbreaktable.htm. Accessed October 15, 2015.

22. Petersen BT, Chennat J, Cohen J, Cotton PB, Greenwald DA, Kowalski TE, et al. Multisociety guideline on reprocessing flexible GI endoscopes: 2011. Infect Control Hosp Epidemiol 2011;32:527-37.

23. Gerding DN, Peterson LR, Vennes JA. Cleaning and disinfection of fiberoptic endoscopes: evaluation of glutaraldehyde exposure time and forced-air drying. Gastroenterology 1982;83:613-8.

24. Kovaleva J, Degener JE, van der Mei HC. Mimicking disinfection and drying of biofilms in contaminated endoscopes. J Hosp Infect 2010;76:345-50.

25. Rutala WA, Weber DJ. Disinfection and sterilization in healthcare facilities. In: Han J, editor. SHEA practical healthcare epidemiology. Chicago (IL): University of Chicago Press; 2016.

26. Weber DJ, Rutala WA. Role of environmental contamination in the transmission of vancomycin-resistant enterococci. Infect Control Hosp Epidemiol 1997;18:306-9.

27. Tosh PK, Disbot M, Duffy JM, Boom ML, Heseltine G, Srinivasan A, et al. Outbreak of Pseudomonas aeruginosa surgical site infections after arthroscopic procedures: Texas, 2009. Infect Control Hosp Epidemiol 2011;32:1179-86.

28. Roberts CG. Studies on the bioburden on medical devices and the importance of cleaning. In: Rutala WA, editor. Disinfection, sterilization and antisepsis: principles and practices in healthcare facilities. Washington, DC: Association for Professionals in Infection Control and Epidemiology; 2000:63-9.

29. Alfa MJ, Degagne P, Olson N. Worst-case soiling levels for patient-used flexible endoscopes before and after cleaning. Am J Infect Control 1999;27:392401.

30. Society of Gastroenterology Nurses and Associates. Standards of infection control and reprocessing of flexible gastrointestinal endoscopes. Gastroenterol Nurs 2013;36:293-303.

31. Muscarella LF. Risk of transmission of carbapenem-resistant Enterobacteriaceae and related "superbugs" during gastrointestinal endoscopy. World J Gastrointest Endosc 2014;6:457-74.

32. Ofstead CL, Wetzler HP, Doyle EM, Rocco CK, Visrodia KH, Baron TH, et al. Persistent contamination on colonoscopes and gastroscopes detected by biologic cultures and rapid indicators despite reprocessing performed in accordance with guidelines. Am J Infect Control 2015;43:794-801. 
33. Food and Drug Administration. FDA orders recall under consent decree for all Custom Ultrasonics automated endoscope reprocessors. November 13, 2015. Available from: http://www.fda.gov/NewsEvents/Newsroom/PressAnnouncements/ ucm472605.htm. Accessed October 15, 2015.

34. Carbonne A, Thiolet JM, Fournier S, Fortineau N, Kassis-Chikhani N, Boytchev I, et al. Control of a multi-hospital outbreak of KPC-producing Klebsiella pneumoniae type 2 in France, September to October 2009. Euro Surveill 2010;15.

35. Rutala WA, Weber DJ. Gastrointestinal endoscopes: a need to shift from disinfection to sterilization? JAMA 2014;312:1405-6.

36. Rutala WA, Weber DJ. FDA labeling requirements for disinfection of endoscopes: a counterpoint. Infect Control Hosp Epidemiol 1995;16:231-5.

37. Food and Drug Administration. Brief summary of the gastroenterology and urology devices panel meeting. Food and Drug Administration; 2015.

38. Pajkos A, Vickery K, Cossart Y. Is biofilm accumulation on endoscope tubing a contributor to the failure of cleaning and decontamination. J Hosp Infect 2004;58:224.

39. Roberts CG. The role of biofilms in reprocessing medical devices. In: Rutala WA editor. Disinfection, sterilization and antisepsis: principles, practices, current issues, new research, and new technologies. Washington, DC: Association for Professionals in Infection Control and Epidemiology; 2010:223-9.

40. Neves MS, Gomes da Silva M, Ventura GM, Cortes PB, Duarte RS, de Souza HS Effectiveness of current disinfection procedures against biofilm on contaminated GI endoscopes. Gastrointest Endosc 2015; doi:10.1016/j.gie.2015.09.016.

41. Ren-Pei W, Hui-Jun X, Ke Q, Dong W, Xing N, Zhao-Shen L. Correlation between the growth of bacterial biofilm in flexible endoscopes and endoscope reprocessing methods. Am J Infect Control 2014;42:1203-6.

42. Agrawal D, Muscarella LF. Delayed reprocessing of endoscopes. Gastrointest Endosc 2011:73:853-4.

43. Olympus. Urgent safety notification. Important updated labeling information: new reprocessing instructions for the Olympus TJF-Q180V Duodenoscope. Available from: http://medical.olympusamerica.com/sites/default/files/pdf/ 150326_TJF-Q180V_Customer_letter.pdf. Accessed February 19, 2016.

44. Rutala WA, Weber DJ. Outbreaks of carbapenem-resistant Enterobacteriaceae infections associated with duodenoscopes: what can we do to prevent infections? Am J Infect Control 2016;44:e47-51.

45. Murphy C. Inactivated glutaraldehyde: lessons for infection control. Am J Infect Control 1998;26:159-60.

46. Carsauw H, Debacker N. Recall of patients after use of inactive batch of Cidex disinfection solution in Belgian hospitals. Proceedings of the Fifth International Conference of the Hospital Infection Society; 2002 Sept 15-18; Edinburgh, Scotland. London, England: Hospital Infections Society. 2002.

47. Collins WO. A review of reprocessing techniques of flexible nasopharyngoscopes. Otolaryngol Head Neck Surg 2009;141:307-10.

48. Cavaliere M, Iemma M. Guidelines for reprocessing nonlumened heat-sensitive ear/nose/throat endoscopes. Laryngoscope 2012;122:1708-18.

49. Alvarado CJ, Anderson AG, Maki DG. Microbiologic assessment of disposable sterile endoscopic sheaths to replace high-level disinfection in reprocessing: a prospective clinical trial with nasopharygoscopes. Am J Infect Control 2009;37:408-13.

50. Elackattu A, Zoccoli M, Spiegel JH, Grundfast KM. A comparison of two methods for preventing cross-contamination when using flexible fiberoptic endoscopes in an otolaryngology clinic: disposable sterile sheaths versus immersion in germicidal liquid. Laryngoscope 2010;120:2410-6.

51. Durand ML, Weber DJ, Rutala WA. Healthcare-associated eye infections. In: Mayhall CG, editor. Hospital epidemiology and infection control. Philadelphia, PA: Wolters Kluwer; 2012:352-64.

52. Centers for Disease Control and Prevention. Recommendations for preventing possible transmission of human T-lymphotropic virus type III/lymphadenopathy -associated virus from tears. MMWR Morb Mortal Wkly Rep 1985;34:533-4.

53. Rutala WA, Peacock JE, Gergen MF, Sobsey MD, Weber DJ. Efficacy of hospital germicides against adenovirus 8 , a common cause of epidemic keratoconjunctivitis in health care facilities. Antimicrob Agents Chemother 2006;50:1419-24.

54. Tyler R, Ayliffe GA, Bradley C. Virucidal activity of disinfectants: studies with the poliovirus. J Hosp Infect 1990;15:164-6.

55. Sattar SA, Springthorpe VS, Karim Y, Loro P. Chemical disinfection of non-porous inanimate surfaces experimentally contaminated with four human pathogenic viruses. Epidemiol Infect 1989;102:493-505.

56. Chronister CL. Structural damage to Schiotz tonometers after disinfection with solutions. Optom Vis Sci 1997;74:164-6.

57. Koo D, Bouvier B, Wesley M, Courtright P, Reingold A. Epidemic keratoconjunctivitis in a university medical center ophthalmology clinic; need for re-evaluation of the design and disinfection of instruments. Infect Control Hosp Epidemiol 1989;10:547-52.

58. Jernigan JA, Lowry BS, Hayden FG, Kyger SA, Conway BP, Gröschel DH, et al. Adenovirus type 8 epidemic keratoconjunctivitis in an eye clinic: risk factors and control. J Infect Dis 1993;167:1307-13.

59. Milki AA, Fisch JD. Vaginal ultrasound probe cover leakage: implications for patient care. Fertil Steril 1998;69:409-11.

60. Storment JM, Monga M, Blanco JD. Ineffectiveness of latex condoms in preventing contamination of the transvaginal ultrasound transducer head. South Med J 1997;90:206-8.

61. Fritz S, Hust MH, Ochs C, Gratwohl I, Staiger M, Braun B. Use of a latex cover sheath for transesophageal echocardiography (TEE) instead of regular disinfection of the echoscope? Clin Cardiol 1993;16:737-40.
62. Hignett M, Claman P. High rates of perforation are found in endovaginal ultrasound probe covers before and after oocyte retrieval for in vitro fertilizationembryo transfer. J Assist Reprod Genet 1995;12:606-9.

63. Kac G, Podglajen I, Si-Mohamed A, Rodi A, Grataloup C, Meyer G. Evaluation of ultraviolet $\mathrm{C}$ for disinfection of endocavitary ultrasound transducers persistently contaminated despite probe covers. Infect Control Hosp Epidemiol 2010;31:16570 .

64. Amis S, Ruddy M, Kibbler CC, Economides DL, MacLean AB. Assessment of condoms as probe covers for transvaginal sonography. J Clin Ultrasound 2000;28:295-8.

65. Rooks VJ, Yancey MK, Elg SA, Brueske L. Comparison of probe sheaths for endovaginal sonography. Obstet Gynecol 1996;87:27-9.

66. Odwin CS, Fleischer AC, Kepple DM, Chiang DT. Probe covers and disinfectants for transvaginal transducers. J Diagn Med Sonogr 1990;6:130-5.

67. Benson WG. Exposure to glutaraldehyde. J Soc Occup Med 1984;34:63-4.

68. Garland SM, de Crespigny L. Prevention of infection in obstetrical and gynaecological ultrasound practice. Aust N Z J Obstet Gynaecol 1996;36:392-5.

69. Kac G, Gueneret M, Rodi A, Abergel E, Grataloup C, Denarié N, et al. Evaluation of a new disinfection procedure for ultrasound probes using ultraviolet light. J Hosp Infect 2007;65:163-8.

70. Fowler C, McCracken D. US probes: risk of cross infection and ways to reduce it-comparison of cleaning methods. Radiology 1999;213:299-300.

71. Muradali D, Gold WL, Phillips A, Wilson S. Can ultrasound probes and coupling gel be a source of nosocomial infection in patients undergoing sonography? An in vivo and in vitro study. AJR Am J Roentgenol 1995;164:1521-4.

72. Casalegno JS, Le Bail Carval K, Eibach D, Valdeyron ML, Lamblin G, Jacquemoud $\mathrm{H}$, et al. High risk HPV contamination of endocavity vaginal ultrasound probes: an underestimated route of nosocomial infection? PLoS ONE 2012;7:e48137.

73. Rutala WA, Gergen M, Sickbert-Bennett EE. Effectiveness of a hydrogen peroxide mist (Trophon $\circledast$ ) system in inactivating healthcare pathogens on surface and endocavitary probes. Infect Control Hosp Epidemiol 2016 Feb 4; 1-2. [Epub ahead of print]

74. Ryndock E, Robison R, Meyers C. Susceptibility of HPV 16 and 18 to high-level disinfectants indicated for semi-critical ultrasound probes. J Med Virol 2015; doi:10.1002/jmv.24421.

75. Vickery K, Gorgis VZ, Burdach J, Patel D. Evaluation of an automated high-level disinfection technology for ultrasound transducers. J Infect Public Health 2014;7:153-60.

76. Gillespie JL, Arnold KE, Noble-Wang J, Jensen B, Arduino M, Hageman J, et al Outbreak of Pseudomonas aeruginosa infections after transrectal ultrasoundguided prostate biopsy. Urology 2007;69:912-4

77. FDA. Public Health Notification: reprocessing of reusable ultrasound transducer assemblies used for biopsy procedures, 2006. 2006. Available from: http://www .fda.gov/MedicalDevices/Safety/AlertsandNotices/PublicHealthNotification/ ucm062086.htm. Accessed November 1, 2009.

78. Lessa F, Tak S, Devader SR, Goswami R, Anderson M, Williams I, et al. Risk of infections associated with improperly reprocessed transrectal ultrasound-guided prostate biopsy equipment. Infect Control Hosp Epidemiol 2008;29:289-93.

79. Masood J, Voulgaris S, Awogu O, Younis C, Ball AJ, Carr TW. Condom perforation during transrectal ultrasound guided (TRUS) prostate biopsies: a potential infection risk. Int Urol Nephrol 2007:39:1121-4

80. U.S. Food and Drug Administration. FDA Public Health Notification: Reprocessing of Reusable Ultrasound Transducer Assemblies Used for Biopsy Procedures. Available from: http://www.fda.gov/MedicalDevices/Safety/AlertsandNotices/ PublicHealthNotifications/ucm062086.htm. Accessed February 19, 2016.

81. Bancroft EA, English L, Terashita D, Yasuda L. Outbreak of Escherichia coli infections associated with a contaminated transesophageal echocardiography probe. Infect Control Hosp Epidemiol 2013;34:1121-3.

82. Seki M, Machida H, Yamagishi Y, Yoshida H, Tomono K. Nosocomial outbreak of multidrug-resistant Pseudomonas aeruginosa caused by damaged transesophageal echocardiogram probe used in cardiovascular surgical operations. J Infect Chemother 2013;19:677-81.

83. Cleaning, Disinfecting, and Sterilizing TEE Transducers. Available from: http://www.healthcare.philips.com/main/products/ultrasound/transducers transducer_care/cleaning_and_disinfecting/tee_transducers.wpd. Accessed October 15, 2015.

84. Kanagala P, Bradley C, Hoffman P, Steeds RP. Guidelines for transesophageal echocardiographic probe cleaning and disinfection from the British Society of Echocardiography. Eur J Echocardiogr 2011;12:i17-23.

85. Venticinque SG, Kashyap VS, O'Connell RJ. Chemical burn injury secondary to intraoperative transesophageal echocardiography. Anesth Analg 2003:97:1260-1.

86. Rutala WA, Gergen MF, Weber DJ. Disinfection of an infrared coagulation device used to treat hemorrhoids. Am J Infect Control 2012;40:78-9.

87. Muscarella LF. Recommendations to resolve inconsistent guidelines for the reprocessing of sheathed and unsheathed rigid laryngoscopes. Infect Control Hosp Epidemiol 2007;28:504-7.

88. Muscarella LF. Prevention of disease transmission during flexible laryngoscopy. Am J Infect Control 2007;35:536-44

89. Muscarella LF. Reassessment of the risk of healthcare-acquired infection during rigid laryngoscopy. J Hosp Infect 2008;68:101-7.

90. Call TR, Auerbach FJ, Riddell SW, Kiska DL, Thongrod SC, Tham SW, et al. Nosocomial contamination of laryngoscope handles: challenging current guidelines. Anesth Analg 2009;109:479-83.

91. Williams D, Dingley J, Jones C, Berry N. Contamination of laryngoscope handles. J Hosp Infect 2010;74:123-8. 
92. Phillips RA, Monaghan WP. Incidence of visible and occult blood on laryngoscope blades and handles. AANA J 1997;65:241-6.

93. McGrath MAC video larynoscope operator's manual. Available from: http://www.vitaid.com/files/mcgrath_mac_operator____manual_.0_-_english .pdf. Accessed October 15, 2015.

94. GlideScope. Available from: http://www.verathon.com/assets/0900-4200 -02-60.pdf. Accessed October 15, 2015

95. Wendelboe AM, Baumbach J, Blossom DB, Frank P, Srinivasan A, Sewell CM. Outbreak of cystoscopy related infections with Pseudomonas aeruginosa: New Mexico, 2007. J Urol 2008;180:588-92.
96. Rutala WA, Gergen MF, Bringhurst J, Weber DJ. Effective high-level disinfection pf cystoscopes" Is perfusion of channels required? Infect Control Hosp Epidemiol 2016;37:228-31.

97. Clemens JQ, Dowling R, Foley F, Goldman HB, Gonzalez CM, Tessier C, et al. Joint AUA/SUNA white paper on reprocessing of flexible cystoscopes. J Urol 2010;184:2241-5

98. Meyers J, Ryndock E, Conway MJ, Meyers C, Robison R. Susceptibility of high-risk human papillomavirus type 16 to clinical disinfectants. J Antimicrob Chemother 2014;69:1546-50. 